\title{
CONSTRUÇÕES SUPERLATIVAS NO PORTUGUÊS BRASILEIRO: TRI [X], BAITA [X] E PUTA [X]
}

\author{
CONSTRUCCIONES SUPERLATIVAS EN PORTUGUÉS BRASILEÑO: TRI [X], BAITA [X] Y \\ PUTA [X]
}
SUPERLATIVE CONSTRUCTIONS IN BRAZILIAN PORTUGUESE: TRI [X], BAITA [X] AND PUTA $[X]$

\author{
Heloísa Pedroso de Moraes Feltes* \\ Marciele Borchert** \\ Universidade de Caxias do Sul
}

RESUMO: Este estudo objetiva explorar construções superlativas a partir da Gramática das Construções (GOLDBERG, 1995, 2006; MIRANDA; SALOMÃO, 2009), tendo como aporte teórico-metodológico central estudos já realizados sobre superlatividade (CARRARA, 2015; MACHADO, 2011). A fim de averiguar expressões produtivas candidatas a construções superlativas no uso coloquial do Português Brasileiro, investigamos as ocorrências das expressões tri (como prefixo), baita e puta, no Corpus do Português. Na análise, consultamos as definições de tri, baita e puta, com o objetivo de elucidar a possível origem e motivação para as expressões. Quanto à formalização, enquadramo-las em padrões propostos nos estudos revisados, com tri como uma Construção Prefixal de Modificação de Grau (CARRARA, 2015); e baita e puta como Construções Superlativas Genéricas (MACHADO, 2011). A análise dos dados possibilitou propor matrizes construcionais e sugerir a ampliação da rede construcional superlativa no Português Brasileiro.

PALAVRAS-CHAVE: Gramática das construções. Construções superlativas. Linguística cognitiva.

RESUMEN: Este estudio tiene por finalidad explorar construcciones superlativas a partir de la Gramática de Construcciones (GOLDBERG, 1995, 2006; MIRANDA; SALOMÃO, 2009), cuyo aporte teórico-metodológico central son estudios realizados sobre superlatividad (CARRARA, 2015; MACHADO, 2011). Buscando averiguar expresiones superlativas productivas en el uso coloquial del Portugués Brasileño, hemos investigado las incidencias de las expresiones tri (como prefijo), baita y puta, en el Corpus do Português. Hemos consultado las definiciones de tri, baita y puta, con el objeto de dilucidar sus posibles origenes y motivaciones. Sobre la formalización, encuadramos las expresiones en patrones propuestos en los estudios revisados, con tri como Construcción Prefijal de Modificación del Grado (CARRARA, 2015); y baita y puta como Construcciones Superlativas Genéricas (MACHADO, 2011). El análisis de los datos ha posibilitado proponer matrices construccionales y sugerir la ampliación de la red construccional superlativa en Portugués Brasileño.

PALABRAS CLAVE: Gramática de construcciones. Construcciones superlativas. Lingüística cognitiva.

\footnotetext{
* Doutora e mestre em Linguística Aplicada pela Pontifícia Universidade Católica do Rio Grande do Sul. Professora dos Programas de Pós-Graduação em Letrase Culturada (UCS) e de Doutorado em Letras, Associação Ampla UCS/ UniRitter. E-mail: helocogn@terra.com.br.

** Mestreem Letras, Cutura e Regionalidade pela Universidade de Caxias do Sul. Licenciadaem Letras-Língua Portuguesa pela UCS. E-mail: marciele_borchert@hotmail.com.
} 
ABSTRACT: This study aims to explore superlative constructions from Construction Grammar (GOLDBERG, 1995, 2006; MIRANDA; SALOMÃO, 2009), having as main theoretical and methodological bases studies on superlativization (CARRARA, 2015; MACHADO, 2011). In order to verify productive superlative expressions in the colloquial use of Brazilian Portuguese, we investigated the occurrences of the expressions tri (as a prefix), baita and puta, in Corpus do Português. We searched definitions of tri, baita and puta, with the objective of eliciting the origin and motivation for the expressions. Regarding the formalization, we fitted them into the patterns proposed by the reviewed studies: tri as Prefixal Degree Modification Construction (CARRARA, 2015); and baita and puta as General Superlative Constructions. The analysis allowed us to propose constructional matrices and the enlargement of the superlative constructional net in Brazilian Portuguese.

KEYWORDS: Construction Grammar. Superlative constructions. Cognitive Linguistics.

\section{INTRODUÇÃO}

A tradição gramatical oferece diversas alternativas para construir o superlativo. Porém, por mais variados que sejam os recursos oferecidos em uma perspectiva normativa da língua, esses não dão conta da variedade expressiva da superlatividade, tanto na fala como na escrita, no presente caso, do Português Brasileiro. Na verdade, há recursos criados pelos falantes para expressar a superlatividade não descritos e exemplificados nas gramáticas normativas.

Nossa proposta foi a de explorar estudos já existentes no Brasil que se servem da Gramática das Construções, mormente as produções geradas pelo grupo de pesquisa Gramática e Cognição, coordenado pela Profa. Dra. Neusa Salim Miranda, no âmbito dos estudos sobre construções superlativas, os quais já alcançaram maturidade. Por essa razão, seguimos a proposta teóricometodológica da Gramática das Construções, mantendo a linha de investigação já traçada para estudos sobre superlatividade no Português Brasileiro, no sentido de ampliarem-se os estudos por essa abordagem, de modo a colaborar com a avaliação de sua adequação descritivo-explanatória.

O objetivo geral deste artigo é o de examinar três expressões utilizadas com função superlativa e intensificadora no Português Brasileiro, propondo matrizes construcionais.

O aporte teórico central de nossa pesquisa abrange os estudos de Carrara (2015), Machado (2011) e Goldberg (1995, 2006), na formulação da base da Gramática das Construções; Miranda e Salomão (2009), com relação às construções em Língua Portuguesa; e autores importantes para situar a Gramática das Construções, a saber, Croft e Cruse (2004), Salomão (2002), Miranda e Machado (2014), Fillmore (1979), Fillmore, Kay e O’Connor (1988), Lakoff (1987) e Evans (2007).

O artigo está organizado em quatro seções. A primeira seção situa a Gramática das Construções, nossa perspectiva teórica central, a partir dos compromissos epistemo-teórico-metodológicos da Linguística Cognitiva assumidos por esses autores. A segunda seção apresenta a Construção Superlativa Genérica e a Construção Prefixal de Modificação de Grau, que são as construções de base para nossa análise. A seção 3 trata do método, técnicas e procedimentos adotados no estudo. Na seção 4, analisam-se as expressões com valor superlativo, a partir das matrizes de construções superlativas já levantadas na seção 2. Em nossa pesquisa, de natureza exploratória, analisam-se tri (como prefixo), baita e puta. Para a compilação das ocorrências dessas expressões, utilizamos o Corpus do Português, especificamente em Web/Dialetos

\section{GRAMÁTICA DAS CONSTRUÇÕES E LINGUÍSTICA COGNITIVA}

Partindo de uma abordagem geral dos compromissos epistemo-teórico-metodológ icos da Linguística Cognitiva, esta seção objetiva caracterizar a Gramática das Construções em suas teses, conceitos ecaracterísticas mais centrais. 
As gramáticas normativas não tratam dos usos efetivos de várias expressões de uma língua. As regras da gramática normativa dizem respeito ao que é padrão na modalidade escrita da variedade "culta" da língua, e seu foco não éa linguagem em sua riqueza expressiva, como um fenômeno sociocognitivo.

Na perspectiva da Linguística Cognitiva, a faculdade da linguagem é uma habilidade cognitiva humana, que utiliza o mesmo aparato cognitivo de outras tarefas, afirmam Croft e Cruse (2004). Tal suposição se diferencia da premissa gerativista de que o ser humano possui uma capacidade inata e autônoma exclusivamente para a linguagem. A principal preocupação da Linguística Cognitiva é demonstrar o papel das habilidades cognitivas gerais na linguagem. Conforme os autores:

A linguagem é uma habilidade cognitiva distintivamente humana, certamente. A partir de uma perspectiva cognitiva, a linguagem é a percepção e produção em tempo real de uma sequência temporal de unidades discretas, estruturadas e simbólicas. Essa configuração particular das habilidades cognitivas é provavelmente única à linguagem, mas as habilidades cognitivas requeridas não o são. (CROFT; CRUSE, 2004, p. 2, tradução nossa).

Para os autores, três hipóteses principais guiam a abordagem da linguagem pela Linguística Cognitiva: (a) a linguagem não é uma faculdade cognitiva autônoma; (b) gramática é conceptualização; e (c) o conhecimento da língua emerge do uso da língua.

A Linguística Cognitiva defende que as representações sintática, morfológica e fonológica são basicamente conceptuais, e, embora sons, e até os enunciados, sejam entidades físicas, eles precisam ser compreendidos e produzidos através de processos mentais. Portanto, há processos cognitivos envolvidos na interação linguística, e tais processos utilizados para a linguagem não são muito diferentes daqueles usados para outras tarefas cognitivas, tais como a percepção visual, o raciocínio ou a atividade motora, de acordo com Croft e Cruse (2004).

As abordagens cognitivas para as gramáticas são guiadas por duas teses: a tese simbólica e a tese baseada no uso. Segundo Evans (2007), na tese simbólica a unidade fundamental da gramática é o pareamento forma-significado, e significado e gramática se relacionam e se complementam de forma indissociável. Já para a tese baseada no uso, Evans explica que o conhecimento da língua é o conhecimento de como ela é utilizada, o que significa que um usuário da língua abstrai unidades simbólicas, os enunciados.

A Gramática das Construções é uma abordagem cognitiva linguística da sintaxe, que surgiu a partir de questionamentos fundamentais da Gramática Gerativa. Croft e Cruse (2004) explicam que, de acordo com a maioria das teorias da Gramática Gerativa, o conhecimento gramatical de um falante é organizado em componentes, os quais são, partindo de um princípio geral, fonético, sintático e semântico, perpassados pelo léxico. A ligação entre esses componentes é chamada de linking rules. Segundo os autores, o desenvolvimento da Gramática das Construções rompe a visão componencial da organização gramatical: "[...] por que as linking rules são apenas um conjunto de regras que ligam componentes, enquanto os componentes definem o modo como o conhecimento gramatical é dividido na mente do falante? Como veremos, essa é essencialmente a questão que a gramática das construções pergunta." (CROFT; CRUSE, 2004, p. 227, grifo nosso).

Goldberg (2006, p. 4-5) explica que as abordagens construcionistas compartilham algumas ideias com a corrente gerativista, tais como: (a) a linguagem é considerada como um sistema cognitivo mental; (b) existem combinações de estruturas para criar novos enunciados; e (c) é necessária uma teoria não trivial de aprendizagem da linguagem.

Segundo Goldberg, o termo construcionista tem diferentes motivações:

A motivação primária para o termo é que as abordagens construcionistas enfatizam o papel das CONSTRUÇÕES gramaticais: pares convencionalizados de forma e função. Além disso, as abordagens construcionistas de modo geral enfatizam que as línguas são aprendidas - que elas são CONSTRUÍDAS à base de input juntamente com restrições gerais cognitivas, pragmáticas e de processamento. (2006, p. 3, grifos originais). 
Em termos gerais, a autora esclarece que, na categorização,

[...] a codificação seletiva e a memória imperfeita asseguram que nossos exemplares sejam de alguma maneira abstratos. Nós não armazenamos um número ilimitado de representações completas de enunciados; o que nós mais propriamente retemos são instâncias com algum nível de abstração. Ou seja, nós não retemos passivamente um corpus mental enorme, composto por todas as sequências que já ouvimos, como um computador pode fazer. Ao contrário, nós constantemente dividimos o significado, formamos abstrações, e generalizamos as instâncias que ouvimos. (GOLDBERG, 2006, p. 62, grifo nosso).

Além disso, para a Gramática das Construções, assim como para a Linguística Cognitiva, a gramática é um continuum entre sintaxe e léxico, baseada no uso. Miranda explica que a Gramática das Construções "[...] delineia-se como uma gramática gerativa, simbólica e baseada no uso, que ambiciona a descrição de todas as Construções de uma língua e não distingue criterialmente léxico e gramática." (2009a, p. 11, grifo original).

Uma construção, segundo Goldberg, pode ser reconhecida como tal quando algum aspecto de sua forma ou função não é rigorosamente previsível a partir de seus componentes ou a partir de outra construção existente. Tal concepção reforça a ideia de que uma construção é um pareamento de forma e significado: "Qualquer padrão linguístico é reconhecido como uma construção desde que algum aspecto de sua forma ou função não seja estritamente previsível a partir das partes que a compõem ou de outras construções com existência reconhecida. Além disso, padrões são armazenados como construções mesmo sendo totalmente previsíveis desde que eles ocorram com frequência suficiente." (GOLDBERG, 2006, p. 5).

Além disso, Goldberg (2006) assinala que a abordagem da Gramática das Construções é não derivacional, ou seja, é monoestratal, de modo que não há processos (regras) de transformação em que uma estrutura é “derivada” de outra.

Em suma, como afirma Miranda (2009b, p. 63-64), “[...] a linguagem é prática social e a gramática de uma língua é uma rede de símbolos erguida na cultura" e "[...] o conhecimento linguístico do falante é uma coleção sistemática de pares de forma-função, isto é, de construções aprendidas com base na língua que ouve ao seu redor.”.

Salomão (2009b, p. 38-51), por sua vez, destaca três asserções fundadoras da Gramática das Construções: construções são unidades básicas do conhecimento linguístico; construções são pareamentos de forma-sentido; e a gramática é uma rede de construções.

Se pensarmos a gramática como "[...] um sistema de padrões formais paradigmaticamente contrastáveis e gerativamente combináveis, observado um conjunto de restrições de diversa natureza” (SALOMÃO, 2009b, p. 33), muitas expressões frequentemente utilizadas pelos falantes de uma língua estarão além da compreensão. Tais expressões, afirma Salomão, são comumente deixadas de lado, por não se adequarem às regras prescritas pela gramática, o que configura uma oportunidade para a Linguística contribuir como ciência, tratando das “[...] numerosíssimas construções anteriormente negligenciadas". Há, nesse sentido, o desafio de "[...] descrever todas as construções de uma língua, inclusive aquelas que, por razões teóricas, são reputadas 'desinteressantes'” (SALOMÃO, 2009b, p. 35).

Apesar dos recentes esforços em estudar as construções do Português, Salomão (2009b) explica que nada ainda foi feito que leve a constituir uma versão integrada de uma gramática do Português do Brasil. A importância dessa empreitada reside no fato de que o todo nem sempre éa soma das partes quando se trata das inúmeras expressões de uma língua.

Em um artigo sobre a integração entre sintaxe e léxico, Salomão (2002) retoma brevemente o percurso que antecedeu o surgimento da abordagem construcionista da gramática, mencionando a hipótese gerativa e o quanto esta não contempla o fenômeno do idiomatismo, que origina formações lexicais não composicionais, logo não previsíveis pelo conhecimento do léxico e da sintaxe de uma língua. 
Salomão (2002, p. 67) explica o surgimento de uma Gramática das Construções, que emergiu em Berkeley, no fim dos anos 1980, a partir de três movimentos analíticos, os quais:

(a) estudo das redes polissêmicas: liderado por George Lakoff, reconhece redes construcionais, motivadas por projeções conceptuais, principalmente de natureza figurativa, tendo como instância-núcleo da irradiação uma construção gramatical. Lakoff analisou as construções com there, cuja instância central é a "construção locativa" e a irradiação motivada chega até a "construção existencial";

(b) estudo das fórmulas situacionais (idiomas sintáticos): Fillmore e Kay elaboraram um trabalho em parceria com O'Connor, no qual analisam o marcador discursivo let alone, cuja função é relacionar comparativamente dois eventos evocados por duas orações ligadas por esse conectivo, caso similar aos marcadores proporcionais quanto mais, pormais que, em Português;

(c) estudo da variação das valências: proposto por Goldberg, postula, como solução para verbos que apresentam valências distintas, "uma configuração sintática, pareada com a indicação pragmático-semântica correspondente", em vez de se usar uma valência ad hoc para cada verbo, como propõem os neo-lexicalistas.

Segundo Salomão (2002), o que esses três movimentos têm em comum é a convergência em duas premissas fundadoras: (a) a indistinção entre léxico e gramática, sendo a linguagem uma grande rede construcional, e (b) a concepção do signo linguístico como vetor bipolar indissociável, que pareia forma e condições da construção do sentido, indissoluvelmente semântico-pragmáticas.

Miranda e Machado (2014, p. 121) afirmam que, a partir da teoria da Gramática das Construções,

[...] a construção, vista como um símbolo ou signo, adquire um estatuto teórico de unidade básica do conhecimento linguístico. A partir daí, fenômenos linguísticos, desde os mais idiossincráticos até os mais gerais recebem o mesmo tratamento; todas as unidades linguísticas, em todos os níveis, têm um formato único de descrição, adquirindo contornos construcionais. (MIRANDA; MACHADO, 2014, p. 121, grifo original).

Fillmore (1979) sugere a existência de uma segunda idealização em linguística, que sucede a de falante/ouvinte ideal em uma comunidade de fala homogênea, proposta por Chomsky em 1965: a do falante/ouvinte inocente, aquele que conhece as estruturas gramaticais e as utiliza para elaborar seu discurso e transmitir a mensagem que deseja da forma mais direta possível, sem inferências entre o que diz e o significado que almeja transmitir, atuando como um "decifrador de códigos" (decoder). O autor afirma que o discurso desse tipo de falante/ouvinte "tende a ser lento, chato, e pedante" (FILLMORE, 1979, p. 64). Para Fillmore, ofalante/ouvinte inocente tem diversas limitações importantes: "Resumindo, o falante/ouvinte inocente não sabe sobre expressões idiomáticas lexicais, expressões idiomáticas frasais, colocações lexicais, fórmulas situacionais, comunicação indireta, ou sobre estruturas esperadas de textos de certos tipos." (FILLMORE, 1979, p. 66).

O conceito de falante-ouvinte inocente corrobora a ideia de que o conhecimento gramatical de uma língua, incluindo-se aqui aquele que está nas gramáticas tradicionais, não é suficiente para conferir a um falante amplas habilidades de compreensão. As expressões idiomáticas constituem parte considerável da comunicação. O falante que domina as construções de uma língua conta com um acervo de expressões que têm significado próprio, integral, que não pode ser compreendido separando-se as partes, pois otodo não é formado pela soma das partes, mas sim a composição das partes que forma o todo.

Fillmore, Kay e O’Connor (1988) sugerem que aquilo que é idiomático em uma língua pode ser pensado como um apêndice para a gramática, constituindo um vasto repositório de expressões idiomáticas, que deve incluir descrições de conjuntos de fenômenos importantes e sistemáticos, os quais interagem de modo significativo com o resto da gramática. Os autores defendem que "[...] uma expressão ou construção idiomática é algo que um usuário da língua poderia falhar em conhecer enquanto conhece todo o resto na língua." (1988, p. 504), e estabelecem uma tipologia de expressões idiomáticas, cujos parâmetros são ponto de partida para as várias realizações de construções em uma língua. São elas: 
(a) codificação/decodificação: as primeiras são expressões que não requerem experiência prévia do falante para que este possa compreendê-las, como em answer the door, wide awake e bright red (atender à porta, de olhos bem abertos e vermelho brilhante, respectivamente $)^{1}$, expressões que podem ser compreendidas mesmo quando ouvidas pela primeira vez. As expressões de decodificação são aquelas cujo significado não pode ser entendido apenas pelo conhecimento das palavras que as compõem, e sim pela expressão como um todo, independentemente de seus componentes isolados, como em kick the bucket, que significa literalmente chutar o balde, mas quer dizer morrer, semelhante a bater as botas em Português;

(b) gramaticais/extragramaticais: são gramaticais as expressões que obedecem às regras da gramática, apresentando uma estrutura produtiva, como em kick the bucket, spill the beans e blow one's nose (morrer, contar um segredo e assoar o nariz, respectivamente), constituídas por um verbo seguido de um complemento direto; já as extragramaticais costumam ser idiossincráticas, uma vez que não refletem uma regra sintática geral da língua, como all of a sudden, by and large e so far so good (de repente, no geral e até aqui tudo bem, respectivamente), expressões que não podem ser previstas pelo conhecimento gramatical da língua inglesa. Mesmo possuin do estrutura gramatical, tais expressões não podem ser compreendidas através do conhecimento das regras familiares da gramática e de sua usual aplicabilidade, sendo necessário o conhecimento idiomático para tornar possível a compreensão;

(c) substantivas/formais: as primeiras têm um preenchimento (mais ou menos) previsto de todas as posições em sua estrutura sintática, como em kick the bucket, que prevê itens lexicais específicos; as expressões idiomáticas formais são padrões sintáticos dedicados a propósitos semânticos e pragmáticos não reconhecíveis a partir de sua forma isolada, sendo, portanto, para os autores, o tipo de expressão idiomática que suscita as questões teóricas mais sérias.

A partir dessa ideia, Salomão (2009a) explica que, por ser uma grande rede construcional, a gramática é um continuum entre sintaxe e léxico, calcada no uso linguístico, de modo que as unidades construcionais divergem apenas em sua especificação formal: há construções abertas (a exemplo da construção Sujeito-Predicado), parcialmente especificadas (como a construção proporcional Quanto mais x, mais y) e inteiramente especificadas (como o uso de um sufixo com sentido específico, expressões formulaicas e proverbiais, por exemplo).

Salomão (2009b) menciona que as construções podem ser postuladas como unidades básicas da gramática e explica que o fato de, em algumas expressões linguísticas, o todo não ser a soma das partes foi o ponto crítico que levou a tal postulação. A questão é que o resultado da combinação presente em uma construção pode ser mais complexo do que os elementos que a constituem, conforme explica a autora através do exemplo de carcereiro e prisioneiro, lexemas formados pelo acréscimo do sufixo-eiro e que possuem duas raízes sinônimas (cárcere e prisão), porém o acréscimo do mesmo sufixo aos dois lexemas confere-lhes significados antagônicos e complementares do frame PRISÃO. Dessa forma, para Salomão, a "[...] construção não é matéria de pura combinação sintagmática; ou seja, não é pura forma. Na condição de signo, ela impõe um recorte específico à integração conceptual a que procede.” (2009b, p. 41).

Tendo em vista o exposto até aqui, é importante reforçar que a proposta central da Gramática das Construções diz respeito a uma gramática constituída por uma rede de construções, as quais são motivadas e se relacionam com outras construções em termos de herança. Lakoff (1987) propõe a organização da gramática como uma categoria radial, a partir da qual se tem construções regulares e prototípicas e, em contrapartida, construções específicas e idiossincráticas, que ocupam um lugar periférico e são herdeiras de instâncias centrais. Segundo o autor, os sistemas cognitivos possuem uma ecologia, e o conceito de nicho ecológico é uma parte importante da Gramática das Construções: "[...] quanto mais redundantes são as propriedades de uma dada categoria, mais ela é motivada por sua locação ecológica, e melhor ela se encaixa em um sistema como um todo" (LAKOFF, 1987, p. 493).

Sendo a gramática organizada por redes, tem-se a ideia de conceptualização, que sugere diferentes ligações entre as construções de uma língua. Goldberg (1995) explica os elos (links) que elucidam as relações de herança entre construções. São eles:

${ }^{1}$ As traduções dos exemplos são uma interpretação livre de responsabilidade das autoras deste artigo. 
(a) elo por subparte: neste caso, uma construção é uma subparte de outra e existe independentemente. Um exemplo dado por Goldberg (1995, p. 78) éa Construção de Movimento Intransitiva, como em Kim ran (Kim correu), a qual se relaciona à Construção de Movimento Causado, a exemplo de Kim ran Pat off the street (Kim tirou Pat da rua), que se torna herdeira do primeiro tipo;

(b) elo por instanciação: ocorre quando uma construção é um caso especial de outra, sendo mais específica que aquela que lhe deu origem, como, por exemplo, segundo Goldberg, as acepções do verbo drive, que em sentido primário significa dirigir, mas pode assumir o significado de conduzir a algum estado, como em Kim drove Fred crazy (Kim levou Fred à loucura), na qual o sentido de se dirigir de um lugar a outro é usado para indicar uma mudança de estado;

(c) elo por extensão metafórica: Goldberg (1995, p. 81-89) exemplifica este elo com a Construção de Movimento Causado, como em Joe kicked the bottle into the Yard (Joe chutou a garrafa para o pátio), que se estende metaforicamente para a Construção Resultativa, como em Joe kicked Bob black and blue (Joe chutou Bob até deixá-lo roxo), construções nas quais se tem uma mudança de lugar que se estende a uma mudança de estado;

(d) elo por polissemia: ocorre quando construções apresentam a mesma sintaxe e diferem semanticamente. Como um exemplo de herança por polissemia, Goldberg (1995, p. 75) analisou a Construção Ditransitiva, a qual dá origem a outros quatro padrões de construções, que são, portanto, seus herdeiros. A Construção Ditransitiva é representada por um sujeito, um verbo e dois complementos [S V OBJ1 OBJ2], na qual (1) "X causa Y a receber Z" (Joe gave Sally the ball - Joe deu a bola a Sally). A partir dessa construção, tem-se outras quatro, a saber, (2) "X causa Y a não receber Z" (Joe refused Bob a cookie - Joe negou um biscoito ao Bob), (3) "X age para causar Y a receber Z" (Joe bequeathed Bob a fortune - Joe deixou uma fortuna de herança para Bob), (4) "X proporcion a Y a receber Z" (Joe permitted Chris an apple - Joe concedeu a Chris uma maçã) e (5) "X pretende causar Y a receber Z" (Joe baked Bob a cake - Joe assou um bolo para Bob).

Esses links de herança motivam as construções herdeiras; daí se dizer que uma construção é motivada, contendo algum traço da construção-mãe.

\section{A CONSTRUÇÃO SUPERLATIVA GENÉRICA E A CONSTRUÇÃO PREFIXAL DE MODIFICAÇÃO DE GRAU}

Partimos da matriz da Construção Superlativa Génerica, proposta por Machado (2011), cujo intuito é evidenciar um padrão existente em Português para tratar da superlatividade. A Figura 1 mostra a Formalização da Construção Superlativa Genérica.

\begin{tabular}{|cc|}
\hline SM: <NG & OES $>$ \\
SX: Adj. $\sim$ Adv. & Adv. $\sim$ Afixo \\
\hline
\end{tabular}

Figura 1: Formalização da Construção Superlativa Genérica

Fonte: Machado (2011, p. 75)

Conforme a Figura 1, uma Construção Superlativa Genérica possui em sua semântica (SM) um Núcleo Graduável (NG), que pode ser um adjetivo (ADJ) ou advérbio (ADV) no nível sintático (SX), e um Operador de Escala Superlativa (OES) ${ }^{2}$, representado, sintaticamente, por um advérbio ou por um afixo. Tal matriz genérica considera o superlativo sintético, que dispõe de recurso morfológico (os sufixos), e o superlativo analítico, realizado por meio de estratégia lexical, como o uso tradicional de advérbios de intensidade, até a repetição do adjetivo para intensificar.

${ }^{2}$ Por operador de escala superlativa entende-se qualquer afixo ou lexema que atue no sentido de gerar efeitos intensificadores e de superlatividade. 
Carrara (2015) propõe classificar o uso de prefixos como modificadores de grau, o que se aplica tanto a adjetivos e substantivos como a verbos, e também a alguns advérbios, de acordo com os exemplos por ela utilizados. A pesquisa de Carrara integra o macroprojeto Construções Superlativas Morfológicas do Português (MIRANDA, 2011) e estuda a Construção Prefixal de Modificação de Grau, um dos nódulos dessa rede de construções superlativas mórficas.

Carrara (2015) utilizou a Linguística de Corpus, sendo seu corpus específico constituído pelo Corpus do Português e os corpora pertencentes ao Projeto Floresta Sintática, além de tokens obtidos através do Web Concordancer Beta.

Tendo escolhido os prefixos a serem pesquisados (super-, ultra-, hiper-, mega-, arqui-, maxi-, macro-, mini-, micro-), o número de ocorrências, seguido dos prefixos mais frequentes, é o seguinte: 874 ocorrências através do Web Concordancer Beta, das quais 400 com super-e 102 com maxi-; 359 ocorrências no Corpus do Português, com 156 para micro- e 77 para super-; 588 ocorrências na Floresta Sintática, das quais 194 para macro-, 153 para arqui- e 119 para super-.

A Construção Prefixal de Modificação de Grau constitui-se “[...] de um elemento mórfico, via de regra, antepositivo, que expressa modificação de grau (super-, ultra-, hiper-, mega-, arqui-, maxi-, macro-, mini- e micro-) e que se combina com quatro distintas categorias: substantivos, adjetivos, advérbios e verbos" (CARRARA, 2015, p. 118), conforme esquema de formalização apresentado na Figura 2.

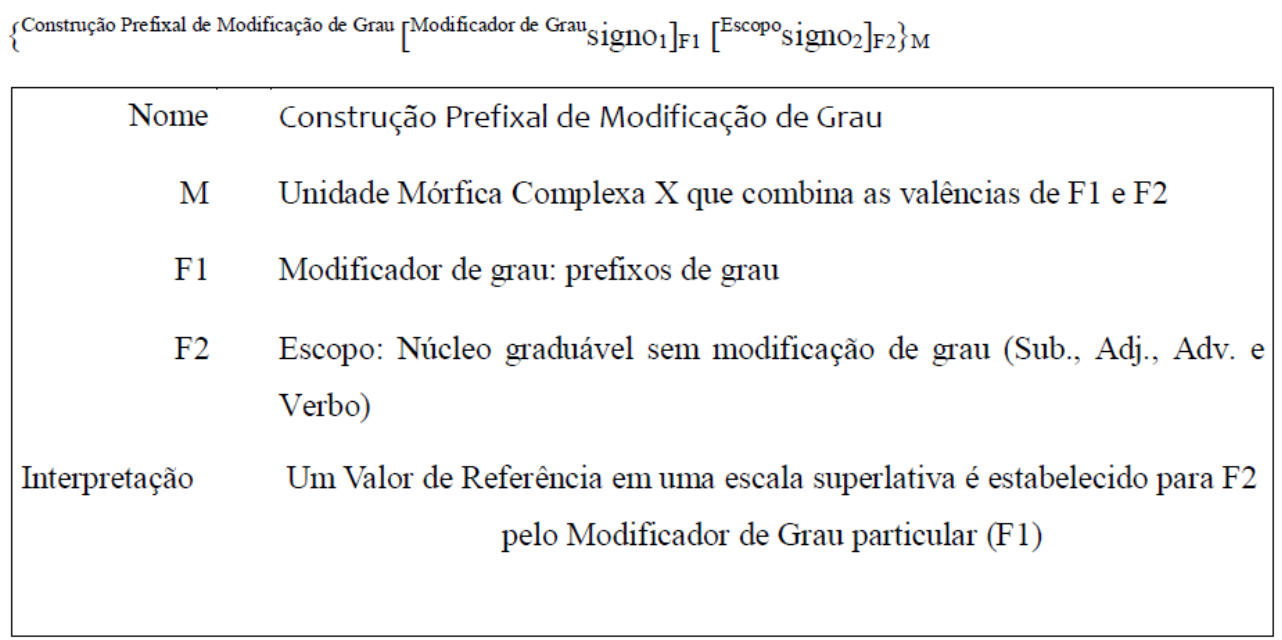

Figura 2: Descrição informal da Construção Prefixal de Modificação de Grau

Fonte: Carrara (2015, p. 132)

Para alcançar seus objetivos, a autora postula duas teses: (a) morfemas são construções; (b) os elementos mórficos antepositivos de grau (super-, ultra-, hiper-, mega-, arqui-, maxi-, macro-, mini-, micro-) são prefixos.

Após definir e exemplificar a Construção Prefixal de Modificação de Grau Substantiva, Carrara explica os subpadrões a ela relacionados:

a) CPMG Substantiva de Tamanho, cujas instâncias são fortemente convencionalizadas, portanto descritas parcialmente pela tradição gramatical e linguística, como formações prefixais marcadas pelo grau aumentativo ou diminutivo. Alguns exemplos retirados dos corpora são maxi acessórios, macro região, mini coelhos, micro vestido;

b) a CPMG Substantiva Polissêmica, cujo sentido construcional, embora único, depende do contexto discursivo. Carrara cita os exemplos hiper inflação, ultra maratonistas, mega unhas, super carro, arqui modelo, inseridos nos respectivos trechos de onde foram retirados, explicando que hiper inflação remete à propriedade Dimensão; ultra maratonistas remete a Condicionamento; mega unhas remete a Tamanho; super carro remete à Potência; e arqui modelo remete à Qualidade (p. 153). 
Além da Construção Prefixal de Modificação de Grau Substantiva, Carrara apresenta a Construção Prefixal de Modificação de Grau Predicadora, que cumpre, segundo a autora, "[...] uma função semântica bastante transparente, qual seja, a de intensificação de seu escopo." (2015, p. 161). Como esse tipo de construção apresenta diferentes escopos, são apresentados separadamente:

a) EC Escopo adjetivo: $\{$ [super-, ultra-, hiper-, mega-, arqui- Modificador de Grau]F1[adjetivoEscopo]F2\}CPMGP redicadora Exemplos: super fofos, jeito ultra fashion, hiper técnico, projeto mega bacana, arqui rival.

b) EC Escopo advérbio: $\{[$ super-, hiper-, mega- Modificador de Grau]F1[advérbioEscopo]F2\}CPMG Predicadora Exemplos: super bem, hiper tarde.

c) EC Escopo verbo: $\{$ [super-, ultra-, hiper-, mega- Modificador de Grau]F1[verboEscopo]F2\}CPMG Predicadora Exemplos: super amei, super gostei, super recomendo, mega curti, hiper amei, ultra curti.

Carrara (2015) assinala que esse tipo de construção é bem produtivo, totalizando 341 ocorrências (19\% do total) dos exemplos contidos nos corpora analisados. A autora constatou também, através de uma pesquisa nas gramáticas e manuais de morfologia, a ausência de instâncias da Construção Prefixal de Modificação de Grau com escopo advérbio, sendo que a gradação mórfica destes ocorre, em geral, em termos de sufixação. Além disso, o baixo número de ocorrências aponta para o baixo grau de convencionalização e produtividade dessas construções, que representam 1\% do total das ocorrências do corpus.

Por fim, a autora apresenta exemplos nos quais o escopo é uma Instanciação Nula e explica que os gramáticos e estudiosos da área nomeiam esses casos de formas livres dos prefixos. Um exemplo, oferecido na tese:

"A gente tem um convidado para hoje. Meu \{[super, hiperModificador de Grau/Prefixo]F 1 [Instanciação NulaEscopo]F2\}CPMG, sei lá, o quê... - O cara é foda. Nando Reis. Quero chamar ele pra tocar uma música com a gente. (WCB)

<opus.lingfil.uu.se/OpenSubtitles2012/xml/pt_br/.../50361_1of1.xml.gz>”. (CARRARA, 2015, p. 175).

A partir dos exemplos citados por Carrara, podemos observar que nos casos de escopo nulo o sentido é marcadamente positivo, como neste apresentado pela autora:

"Se há forma de vida inteligente? Mas será que algum dia vamos encontrar uma raça superior? Se acontecer, será muito super! - Será incrível! Isto acontecerá um dia. Porquê não conosco? (WCB) $<$ hypescience.com/nao-existe-vida-inteligente-fora-da-terra-segundo-cient...>”. (CARRARA, 2015, p. 179).

Carrara explica que o fato de os prefixos estarem sendo intensificados, como em super maxi, muito super e bem maxi, revela a sua convencionalização como formas livres, que perderam, nesses exemplos, a sua consciência de prefixo.

O objetivo de nosso estudo é partir dessa categorização de construções superlativas para analisar um conjunto de expressões cujas ocorrências foram buscadas no Corpus do Português. Nessa análise, verificamos a produtividade dos padrões construcionais já estudados, a possibilidade de encontrar alguma variação de padrões e a necessidade de ampliar os estudos sobre a superlatividade, no caso em que não há, ainda, uma construção identificada da qual algumas expressões possam ser instanciações. 


\section{MÉTODO, TÉCNICAS E PROCEDIMENTOS}

O presente estudo caracteriza-se como uma pesquisa de natureza exploratória e primariamente qualitativa, para identificar e analisar expressões intensificadoras/superlativas a partir de um corpus de língua em uso.

Para tal, utilizamos o Corpus do Português, que contém uma seção de dialetos (Web dialetos), com aproximadamente um bilhão de palavras retiradas de cerca de um milhão de páginas da internet, fator crucial para possibilitar nossa busca, uma vez que as expressões que pesquisamos estão presentes, de modo geral, na oralidade, e os textos da internet muito se aproximam dessa modalidade de uso da língua.

As expressões pesquisadas foram tri, baita e puta, cujas ocorrências foram contabilizadas em planilhas do Microsoft Excel, separando-se os diversos escopos de cada expressão. Para fins de análise, selecionamos um conjunto representativo de ocorrências para demonstrar o funcionamento de cada forma. Cada linha de concordância foi copiada do quadro de origem, teve sua fonte indicada, em nota de rodapé, e foi numerada a partir de (1) nesta seção.

Constatou-se a existência de ocorrências das expressões escolhidas no campo lista da página inicial do Corpus do Português. Quando o resultado foi superior a 2.000 ocorrências, julgamos relevante, para evidenciar um padrão de uso, analisar os colocados até a frequência de ocorrência 2 (inclusa). Essa análise foi realizada manualmente, por meio das linhas de concordância e acesso ao texto integral nos links respectivos nos quadros do Corpus do Português. Tal análise quanti-qualitativa manual visou indentificar o uso das referidas expressões como intensificadores/superlativos e, no processo, foram excluídos os casos de repetição não justificados ${ }^{3}$. Os critérios para a análise via colocados ${ }^{4}$ de cada expressão estão descritos em suas respectivas análises, nas seções seguintes, de modo que o que apresentamos aqui diz respeito aos procedimentos gerais adotados.

O Quadro 1 ilustra as formas que elegemos, seguidas de um exemplo retirado do Corpus do Português.

\begin{tabular}{|c|c|c|}
\hline \multicolumn{2}{|r|}{ Formas } & Exemplos \\
\hline 1. & $\begin{array}{l}\text { tri }[\mathrm{AD}]] \\
\operatorname{tri}[\varnothing] \\
\operatorname{tri}[\mathrm{ADV}] \\
\operatorname{tri}[\mathrm{N}]\end{array}$ & $\begin{array}{l}\text { "Mas sou tri ciumenta, tenho que me tratar." } \\
\text { "[...] tem também a Kings Road, que é tri pra fazer compras também" } \\
\text { "Mas sabe que funcionou tri bem?" } \\
\text { "[...] achei tri massa, daí deixei a preguiça de lado e coloquei no } \\
\text { google [...]" }\end{array}$ \\
\hline 2. & $\begin{array}{l}\text { baita }[\mathrm{N}] \\
\text { baita }[\mathrm{ADJ}]\end{array}$ & $\begin{array}{l}\text { “[...] o qual poderá representar uma baita oportunidade de negócio } \\
\text { para muitos." } \\
\text { “[...] meu deus baita da hora eu amei este jogo barbie!" }\end{array}$ \\
\hline 3. & $\begin{array}{l}\text { puta }[\mathrm{N}] \\
\text { puta [ADJ] }\end{array}$ & $\begin{array}{l}\text { "Eu tomei um puta susto quando isso aconteceu [...]" } \\
\text { "Fico puta arrasada com essas coisas que aumentam o preço só } \\
\text { porque ficam famosas." }\end{array}$ \\
\hline
\end{tabular}

Quadro 1: Forma das expressões superlativas/intensificadoras

Fonte: Elaborado pelas autoras.

\footnotetext{
${ }^{3}$ Isso significa que, conforme observações no próprio site do corpus, há repetições por erro na compilação. Nesses casos, os administradores do corpus sistematicamente eliminam tais repetições, mas, mesmo assim, apenas o uso permite que sejam identificadas as repetições indevidas. As repetições justificadas dizem respeito a trechos que reproduzem enunciados na forma de citação em outros textos, caracterizando-se, assim, seu caráter de discurso repetido e, portanto, de nova ocorrência de uso. Nesses casos, apenas a análise manual permite que essas ocorrências sejam identificadas.
}

${ }^{4} \mathrm{O}$ campo colocados permite verificar os elementos que antecedem e sucedem uma palavra ou expressão. 
É importante alertar que o Corpus do Português está em constante atualização, razão pela qual o número de ocorrências apresentadas nas próximas seções pode divergir daqueles que venham a ser pesquisados futuramente.

\section{ANÁLISE E DISCUSSÃO DOS DADOS}

Nesta seção, são analisadas e discutidas as construções superlativas e intensificadoras a partir da Gramática das Construções. Na análise, verificamos os casos que se enquadram em construções superlativas/intensificadoras já encontradas para o Português Brasileiro.

\subsection{TRI}

Tri como prefixo intensificador parece ser usado tipicamente no Rio Grande do Sul. Por exemplo, na letra da música Deu pra ti, da dupla Kleiton e Kledir, uma homenagem a Porto Alegre, cidade capital do Rio Grande do Sul, encontram-se as expressões trilegal e tri afim, nos seguintes versos: "Vou pra Porto e bah! Tri legal" e "As gurias tão tri afim". De qualquer modo, mesmo que tri tenha uso corrente nesse estado, não significa que não seja empregado em outras regiões do Brasil.

Fischer (1999, p. 161) afirma que tri é um advérbio de uso universal que significa, em geral, muito, por exemplo em "um sorvete tribom" ou "um jogo tridisputado", e diz haver duas teorias bem difundidas na cidade de Porto Alegre sobre a origem dessa expressão: uma atribui a origem do termo tri à conquista da Copa do México, em 1970, podendo também estar associada a uma vitória do Internacional (um dos dois times tradicionais do Rio Grande do Sul) em um tri estadual; a outra hipótese do surgimento de tri significando muito está relacionada ao uso de um medicamento chamado Trimedal, que resultou em doping no futebol.

O autor também menciona trídi, uma variação de tri, um encurtamento de tri-de-bom, mas que se usa isoladamente, sem se combinar com outros adjetivos, por exemplo, "Que tal tava o churra? "Trídi.", e trilegal, "[f]orma usual de elogio para qualquer coisa positiva ou pessoa considerada legal, correta, agradável, etc.” (FISCHER, 1999, p. 161).

Bossle (2003, p. 506) define tri como um advérbio de intensidade muito usado, que significa "[m]uito, bastante: Ele ficou tri faceiro com a pilcha nova. De largo uso entre os gaúchos. (Parece vir das três vezes em que o Inter foi campeão nacional, 75, 76 e 79).”. A explicação para o surgimento da expressão coincide com uma das hipóteses levantadas por Fischer (1999). Há, ainda, o verbete trilegal, classificado como adjetivo, significando muito bom, muito legal (BOSSLE, 2003, p. 506). Nos dicionários de Língua Portuguesa não foram encontrados significados de tricomo intensificador, apenas a referência a três.

A busca por tri no campo lista do Corpus do Português resultou em 1886 ocorrências. Como a frequência foi inferior a 2.000 , contabilizamos todos os resultados na opção colocados, 1.616 ocorrências no total, com as seguintes opções de busca: 0 casas à esquerda e 1 à direita, ocorrências com o valor 1.000 (efetuamos buscas com valor até 3.000, mas o resultado permaneceu o mesmo) e ocorr pcec (que representa o número de resultados para uma pesquisa de concordâncias) com um valor de 200. Das 1.616 ocorrências, analisadas todas as linhas de concordância e eliminados os casos que não indicam intensificação/superlatividade ${ }^{5}$, as repetições e os exemplos de outros países que não o Brasil, restaram 178 ocorrências de tri com sentido intensificador/superlativo, com os seguintes escopos, conforme Quadro 2.

\footnotetext{
${ }^{5}$ Esses casos abrangem tri campeão e tri campeonato (a maioria das ocorrências), tanto seguido das palavras campeão e campeonato quanto com elas subentendidas; casos de tri como nome próprio, como em nomes de games (Ocidente Monster Hunter 3 Tri), de blogs (Mamy Tri) e sites (Tá Tri), em siglas, como TRI (Teoria de Resposta ao Item), a mais utilizada individualmente, TRI (Tratamento de Incidentes), TRI (Termo de Responsabilidade Institucional) e TRI (Taxa de Retorno sobre o Investimento), e em tri como trilhão ou como trimestre.
} 


\begin{tabular}{|c|c|}
\hline Tri + escopo & Número de ocorrências \\
\hline $\operatorname{Tr} i[\mathrm{ADJ}]$ & 116 \\
\hline $\operatorname{Tr} i[$ LOC ADJ $(\mathrm{PREP}+\mathrm{N})]$ & 7 \\
\hline $\operatorname{Tr} i[\mathrm{ADV}]$ & 7 \\
\hline $\operatorname{Tr} i[\mathrm{~N}]$ & 4 \\
\hline $\operatorname{Tr} i[\varnothing]$ & 44 \\
\hline Total de ocorrências & $\mathbf{1 7 8}$ \\
\hline
\end{tabular}

Quadro 2: Tri: escopo da intensificação/superlatividade

Fonte: Elaborado pelas autoras.

Trazemos, a seguir, exemplos com cada escopo:

a) Tri [ADJ] e Tri [LOC ADJ (PREP + N)]: neste padrão, tri é associado tanto a adjetivos positivos, como em tri bom e tri massa, quanto a adjetivos negativos, ou que indicam um sentimento ou situação não favorável, como em triassustador, e, ainda, a locuções adjetivas, como tri na dúvida. Os casos de locução adjetiva são minoria, totalizando sete ocorrências (tri a favor, tri na pilha, tri na dúvida, tri na boa e tri a fim, esta última com três ocorrências).

(1) "Ser pai de menina é tri bom, mas tri assustador também.”

(2) "[...]achei tri massa, daí deixei a preguiça de lado e coloquei no google [...]”6

(3) “[... perdendo um tempão e ficando tri na dúvida se estamos fazendo o melhor negócio!”

b) $\operatorname{Tri}[\boldsymbol{A d v}$ ]: o escopo adverbial foi o segundo menos frequente, perdendo apenas para o substantivo. Encontramos sete ocorrências, das quais seis para tri bem e uma para tri mal, advérbios clássicos, mas nada impede que se combine com outros, como tri tarde, tri cedo etc. O exemplo (4) ilustra o escopo adverbial.

(4) "Graças a seus vídeos passei a ser mais vaidosa e estou me sentindo tri bem”

c) Tri [N]: encontramos quatro casos de tri com escopo substantivo ${ }^{7}$, cuja principal função é a de intensificar as características pressupostas pelo substantivo que o sucede, por exemplo, no caso de tri fã tri reforça o sentimento de apreço sugerido por fã. O mesmo ocorre com tri clichê e tri vítima, situações nas quais as características do que é ser clichê e vítima ganham proporção maior que a normal.

\footnotetext{
${ }^{6}$ Segundo o Dicionário de baianês, de Nivaldo Lariú ([1992], 2014), massa significa legal, joia, esta última também com sentido conotativo, podendo ter surgido, segundo Lariú (em entrevista), na década de 1970, provavelmente devido a uma música de Caetano Veloso, intitulada Massa real, cuja letra levaa acreditar que massa real seja algo muito bom, pois o compositor declara querer apenas coisas boas, o que inclui a massa real). Outra possível interpretação, deixando de lado a definição de Lariú, poderia ser de massa real como as pessoas que participam do carnaval, já que em outras canções da MPB, como em Na massa, de Arnaldo Antunes, massa significa multidão, conforme acepção normal mente contemplada nos dicionários. No caso de tri massa, o significado fornecido pelo Dicionário de baianês é o que se adequa ao sentido que verificamos para a expressão, de algo que é muito bom, muito legal.

${ }^{7}$ A distinção entre substantivos e adjetivos muitas vezes é controvertida. Neste artigo, a distinção é feita com base no comportamento sintático, na aceitação de um DET antecessor ou de um qualificativo posterior (preposicionado ou não). No caso de nossas suposições estarem equivocadas, a consequência é a de que o número de contextos tri [N], como tri [Subst] cai consideravelmente, mantendo-se tri [ADJ] com maior frequência, conforme revelam os dados.
} 
(5) “[...] meu pai é tri fã de carteirinha não perde um programa."

(6) "A combinação de sabores é tão correta que vou ter que usar uma frase que eu acho tri clichê, mas enfim... "é uma explosão de sabor!"."

(7) "Quanto mais iludido, acreditando em milagres, que as novidades mais caras são a solução para acertar dificuldades de saúde e maus hábitos alimentares e de vida, tri vítima será.”

d) Tri $\varnothing$ : o escopo nulo se revelou profícuo: 44 ocorrências, das 178 totais, representando quase $1 / 4$ dos resultados. Uma característica observável nos exemplos com escopo nulo éa referência a algo agradável.

(8) "Na última semana passamos alguns dias em Bento Gonçalves fazendo um trabalho bem legal -- que em breve vai estar por aqui;) -- na companhia de um pessoal tri."

(9) “Só mais uma: desconfie toda vez que Rodrigo (Spinelli) Rosp disser Bah, que tri. Aviso: ele não é gaúcho, é carioca.”

(10) “[... queria dizer que a lista tá bem "Tri” (como se fala aqui pelas bandas do RS)."

Os exemplos (9) e (10) fazem menção a ser coisa de gaúcho falar tri, o que pode ser uma evidência, neste caso com escopo nulo, de que se trata, provavelmente, de um hábito mais comum no Rio Grande do Sul. Apesar de termos contabilizado apenas exemplos do Brasil, apresentamos um exemplo de Moçambique por mencionar que tri é fala de gaúcho: "Gaúcho fala 'tri', eu estava com mania de falar 'mega', moçambicano fala 'maningue'."

Observa-se, ainda, nos exemplos (11) ao (14), casos de muito tri, super tri, muito tri mesmo e tri tri tri tri legal, exemplos de intensificação do intensificador, também observados por Carrara (2015), que considera esses casos como hiperbólicos, uma vez que o superlativo se torna uma forma convencionalizada, perdendo sua força expressiva. A autora explica que, a fim de assegurar o impacto de seu discurso, ofalante recorre a uma escala de intensificação que vai do superlativo à hipérbole, por meio do uso de mais de um prefixo indicador de superlatividade (CARRARA, 2015, p. 200).

\section{(11) “[...] Como dizemos cá no sul 'muito tri'!!!”}

(12) "Oi minha linda Pepinha, que beleza esses encontros, e super tri a Margarete."

(13) "Fred, curto muito teus textos. São muito tri mesmo."

(14) “[...] eles são bem simplis como dis eles são tri tri tri tri legal amei conheces-las [...]"

Considerando tri como um prefixo, entendemos que as expressões verificadas no corpus, com seus respectivos escopos, se encaixam nas Construções Prefixais Modificadoras de Grau, propostas por Carrara (2015). Segundo a autora, nessas construções um prefixo confere a ideia de superlatividade a um adjetivo, na maioria dos casos, podendo também ser combinado com substantivos, como em maxi brinco, com verbos, como em hiper amei, e ter também um escopo nulo, como em super, o qual normalmente se refere a algo positivo. Da mesma forma que os prefixos examinados por Carrara, tri possui, conforme Quadro 2, diferentes escopos.

Baseando-nos em Carrara (2015), propomos a matriz construcional para tri, conforme Figura 3. 


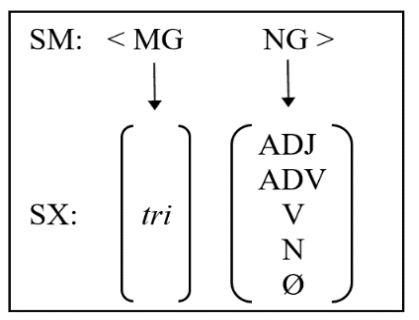

\section{LEGENDA:}

SM: Semântica da Construção

SX: Sintaxe

MG: Modificador de Grau

NG: Núcleo Graduável

Figura 3: Construção Prefixal Modificadora de Grau: tri

Fonte: Elaborado pelas autoras.

\subsection{BAITA}

Geralmente associado a um substantivo, com referência a dimensões, como em baita casa, baita pode também intensificar uma característica, como em baita macho, que intensifica as características do estereótipo do macho gaúcho.

No Quadro 3, apresentamos as definições para o vocábulo baita.

\begin{tabular}{|c|c|}
\hline Aulete $(2011$, p. 193) & $\begin{array}{l}\text { "1. Bras. Pop. Muito grande; ENORME; IMENSO [...] força, intensidade, grande } \\
\text { quantidade etc. [...]2 Muito bom; ÓTIMO; EXCELENTE" }\end{array}$ \\
\hline Bossle (2003, p. 63) & $\begin{array}{l}\text { "adj.2g. 1. Grande, enorme. 2. Crescido. 3. Importante. (Do tupi, mbaê-tatá, coisa } \\
\text { fogosa.)" }\end{array}$ \\
\hline Aurélio (2009, p. 252) & $\begin{array}{l}\text { "1. Grande, enorme, imenso [...] 2. Crescido, desenvolvido. [P. us., pelo menos em } \\
\text { parte do País.]" }\end{array}$ \\
\hline Houaiss et al. (2009, p. 244) & $\begin{array}{l}\text { "adj.2g. (1899) B infrm. } 1 \text { muito grande; imenso, enorme }[\ldots] \mathbf{2} \text { desenvolvido, crescido } \\
{[\ldots] \mathbf{3} \text { fig. cheio de bravura; corajoso, valente, destemido }[\ldots] \mathbf{4} \text { fig. de boa aparência e }} \\
\text { superior qualidade; apreciável, bonito }[\ldots] \mathbf{5} \text { fig. muito bom naquilo que faz; exímio, } \\
\text { excelente" }\end{array}$ \\
\hline Nunes e Nunes (1984, p. 53) & "adj. Grande, crescido, importante. "Que baita homem", isto é, que homem grande!" \\
\hline
\end{tabular}

Baita é classificado com um adjetivo de dois gêneros, que pode indicar tamanho, conferir a ideia de força e intensidade, justificando nosso foco na superlatividade, e pode também se referir à grande quantidade. Sua origem é tida como obscura pelo Aulete. Bossle (2003, p. 63) éo único autor que refere à origem de baita, do tupi.

No Corpus do Português, a busca no campo lista resultou em 4.128 ocorrências. Como as ocorrências excederam 2.000, contabilizamos até a frequência 2 exibida no campo colocados, o suficiente para evidenciar o padrão de expressão superlativa/intensificadora. Eliminados casos de repetição, de exemplos de outros países e de casos de não superlatividade/intensificação, o total de ocorrências foi 2.022. Dessa contagem, temos que baita é seguido ou por um substantivo ou por um adjetivo. No caso do substantivo, temos uma subdivisão: [Art] baita de [N], como em um baita de um profissional ${ }^{8}$, e [Art] baita [N], em um baita texto ${ }^{9}$. O fato de baita ser antecedido de um artigo (em geral indefinido) ou de seguir-se de uma preposição

${ }^{8}$ Os casos nos quais os substantivos não são precedidos por artigo indefinido parecem configurar esquecimento por parte de quem escreveu, como em uma baita de verdade. É visível no exemplo que o mais adequado seria o uso de uma antes de verdade.

${ }^{9}$ Os casos em que baita não é precedido por artigo indefinido são aqueles em que há interjeição, como em baita macho, ou casos em que baita inicia a frase, como em Baita preconceito. 
em que se encontra posposto um artigo indefinido, faz com que os potenciais adjetivos sejam substantivados, em alguns casos. $\mathrm{O}$ Quadro 4 apresenta o total de ocorrências e as respectivas formas encontradas para baita.

\begin{tabular}{|l|l|}
\hline Baita + escopo & Número de ocorrências \\
\hline$[$ Art] baita $[\mathrm{N}]$ & 1973 \\
\hline$[$ Art] baita de $[$ Art] $[\mathrm{N}]$ & 74 \\
\hline baita $[$ Adj] & 1 \\
\hline Total de ocorrências & $\mathbf{2 0 4 8}$ \\
\hline
\end{tabular}

Quadro 4: Baita: escopo da intensificação/superlatividade

Fonte: Elaborado pelas autoras.

Apresentamos, a seguir, exemplos com os respectivos escopos:

a) [Art] baita [N]: este padrão apresentou 74 ocorrências, em um universo de 2.022. Apesar de não ser tão frequente quanto [Art] baita de $[\mathrm{Art}][\mathrm{N}]$, revela um padrão razoável para comprovar a existência da expressão.

(15) "Simples: Bale é um baita jogador, mas, pelo menos ainda, não vale noventa milhões de euros."

(16) "Mas o pouco que se estuda sobre grego e latim por lá, o baita conhecimento que você adquire sobre literatura inglesa (e conseqüentemente sobre a cultura de os países de língua inglesa)...”

Baita pode intensificar diversas características em seus escopos. No exemplo (15), um baita jogador enaltece a qualidade do jogador, sua destreza e competência. Já em (16), baita susto intensifica o impacto causado pelo susto, provavelmente em uma indicação de potência.

b) $[$ Art $]$ baita de [Art] [N]: este caso, embora muito semelhante ao padrão anterior, tem como destaque o uso da preposição de sucedida por um/uma, além do artigo indefinido em posição inicial na expressão, o que confere uma espécie de ênfase adicional. Por exemplo, se dizemos um baita texto, intensificamos as qualidades do substantivo texto, ou podemos, também, estar usando o recurso de superlatividade como uma maneira de ironizar a característica. Já em um baita de um texto, podemos perceber uma intensificação ainda maior, pelo uso reiterado do artigo e pelo acréscimo da preposição de. Parece-nos um bom ponto de partida para pensar nessa variação da expressão [Art] baita [N].

(17) “[... só que esse findi fui em uma festa e vi ele ficando com uma na minha frente, chorei horrores mandei um baita de um texto pra ele, dizendo tudo que sentia, ele demorou dois dias pra responder.”

(18) "Erro $n^{\circ} 1$ de todo mundo que começa é criar um produto e achar clientes. O certo é fazer o inverso. Pw baita de uma postagem boa, parabéns Bruno!"

(19) "Homem que acredita que a namorada é santa e inabalável quanto à fidelidade é um baita de um otário." ${ }^{10}$

c) baita [Adj]: este padrão não resultou produtivo em função de o artigo substantivar os adjetivos usados nos exemplos, conforme explicamos anteriormente. Porém, dos 22 potenciais adjetivos encontrados na compilação das ocorrências, restou a locução adjetiva da hora, como mostra o exemplo (20).

${ }^{10}$ Esse exemplo mostra um caso de um potencial adjetivo (otário) que foi substantivado pelo uso do artigo indefinido 'um'. 
(20) “[... antes de eu não ter orkut eu só jogava barbie meu deus baita da hora eu amei este jogo barbie!”

O exemplo (21) mostra um caso de repetição hiperbólica, o mesmo que se verificou com tri, conforme apresentamos na seção 4.1.

(21) “Zé Ramalho Canta Bob Dylan, álbum que ele lançou há apenas quatro anos, é um baita, baita, baita disco. Inteligente, esperto, gostoso, popular, poético, musical.”

Outro caso que destacamos é o da expressão que baita [N], uma variação que substitui o uso do artigo indefinido pelo que. Nesse caso, o uso mais comum é o de interjeição, denotando surpresa, indignação ou alegria, por exemplo.

(22) “[...] aqui cabe bem a expressão gaúcha: "que baita confusão, tchê!”."11

Propomos que baita se encaixa na Construção Superlativa Genérica, apresentada por Machado (2011), conforme Figura 4.

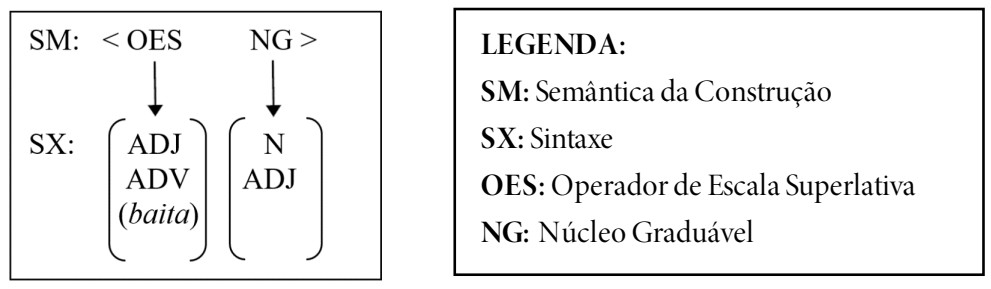

Figura 4: Construção Superlativa Genérica: baita

Fonte: Elaborado pelas autoras.

A Figura 4 traz a adaptação da Construção Superlativa Genérica à expressão baita. Com relação à matriz original, há modificações relevantes. Uma diz respeito ao Operador de Escala Superlativa (OES): no caso de baita, o OES da construção, trata-se de um adjetivo, que ocupa a posição tradicionalmente pertencente a um advérbio ou afixo. Outra mudança está no Núcleo Graduável (NG), que é preenchido, nas expressões com baita, tipicamente por um substantivo (N), havendo casos menos frequentes de adjetivo (ADJ). O superlativo genérico possui como núcleo graduável típico umadjetivo ou um advérbio. Portanto, ao considerar-se baita como um operador de escala superlativa, está-se ampliando o núcleo graduável para outras classes gramaticais e, por consequência, estendendo a superlatividade para além de um núcleo graduável adjetival, como prescrevem as gramáticas normativas tradicionais.

Baita se mostrou um padrão bastante produtivo em termos de expressão de intensificação/superlatividade, considerando as 2.022 ocorrências contabilizadas para nossa análise. Trata-se de um adjetivo que possui valor intensificador, elevando o substantivo que o sucede ao topo da escala da intensificação, um caso que pode ser estudado futuramente em termos mais aprofundados, a fim de verificar todas as ocorrências apresentadas pelo Corpus do Português ou mesmo por outros corpora.

\footnotetext{
${ }^{11}$ Esse exemplo faz referência a baita ser uma expressão gaúcha, indício de que, se não apenas gaúcha, trata-se de uma expressão comumente usada no Rio Grande do Sul.
} 


\subsection{PUTA}

Apesar do significado chulo e ofensivo, o qual costuma ser primeiramente lembrado, puta funciona como um intensificador, um "hiperbolizante" nas palavras de Houaiss et al. (2009), com sentido positivo. Podemos associar o uso de puta ao de baita, pois ambos são comumente combinados com substantivos, a fim de intensificá-los, seja em tamanho, em qualidade ou como algo muito bom. Por exemplo, um puta carro pode ser um carro grande, com todos os acessórios possíveis para o conforto, ou um carro de boa qualidade, caro, desejável. Quem tem uma puta casa provavelmente tem uma casa grande, confortável, dentre outros atributos que o falante possa atribuir à casa, normalmente positivos.

A primeira acepção que os dicionários mostram para puta é a de meretriz, mulher devassa, prostituta, porém apenas o Aulete e o Houaiss apresentam puta como palavra intensificadora. No Aulete, consta que as demais acepções, aquelas não intensificadoras, de prostituta e mulher vulgar, são ofensivas, o que, implicitamente, sugere que como intensificador, puta não é ofensivo. No Houaiss, há uma explicação sobre a gramática e o uso de puta na acepção 3, como hiperbolizante: "na acep. 3, a palavra não tem nenhum teor jocoso ou pejorativo e pode concordar em número ou não com o substantivo que qualifica” (2009, p. 1580).

O resultado da busca no Corpus do Português, em lista, foi 13.807. O critério para a contagem foi o mesmo de baita, uma vez que os resultados excederam 2.000 ocorrências. Tendo contabilizado até a frequência 2 das ocorrências no campo colocados, obtivemos os seguintes resultados: 571 casos de puta sucedido por um substantivo e nove casos seguidos de adjetivo, conforme o Quadro 5.

\begin{tabular}{|l|l|}
\hline Puta + Escopo & Número de tokens \\
\hline Puta $[\mathrm{N}]$ & 571 \\
\hline Puta $[\mathrm{Adj}]$ & 9 \\
\hline Total de ocorrências & $\mathbf{5 8 0}$ \\
\hline \multicolumn{2}{|c|}{ Quadro 5: Puta: escopo da intensificação/superlatividade } \\
Fonte: Elaborado pelas autoras.
\end{tabular}

Apresentamos três exemplos com cada escopo:

a) puta [N]

(23) "[...] eu fiquei com uma puta dor nas pernas depois de uma dança."

(24) "É uma puta vergonha a gente ter que pagar uma puta grana pra tocar na rádio, meu!"

(25) "Reiko começou a namorar o cara, que morava em Montecito, um bairro nobre da cidade, e tinha um puta carrão."

No exemplo (23), a potência de dor é intensificada por puta. Em (24), puta intensifica a proporção da vergonha, sua potência, de certa forma, e puta grana indica grande quantidade. Em (25), carrão já é uma forma intensificada, pois não se trata de falar de um carro grande em tamanho ou dimensões, e a intensificação está sendo reiterada pelo uso de puta como um indicador de alta qualidade, ou de bons atributos. Há também casos como puta filmão, puta filmaço, puta amigão. Em outras ocorrências, há um diminutivo com valor pejorativo, que é intensificado por puta, como em puta futebolzinho, puta entrevistinha, puta discursinho, expressões nas quais o uso do diminutivo visa criticar a qualidade, pô-la em dúvida, situação que é intensificada pelo uso do adjetivo hiperbolizante puta.

b) puta [Adj] 
(26) "Esse sr. vai tomar uma raquetada na orelha que nunca mais ele vai esquecer, puta babaca, se expor por nada"

(27) “[... essa jornalistazinha puta maconheira amiga do caramante não sabe o q fala [...]”

(28) "Fico puta arrasada com essas coisas que aumentam o preço só porque ficam famosas."

Nos casos de puta [Adj], há uma intensificação da característica expressa pelos adjetivos. Em nossa pesquisa no Corpus do Português, dos oito resultados com escopo adjetivo, sete são, aparentemente, negativos. Tal fato não impede que puta não possa ser combinado com adjetivos positivos, mas indica que o padrão usual, dados os resultados, ocorre com características negativas.

A Figura 5 mostra a matriz construcional para puta.

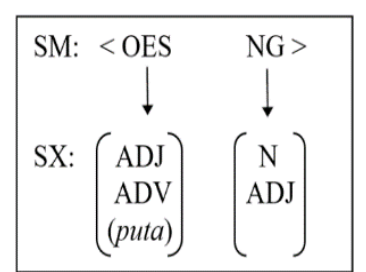

Figura 5: Construção Superlativa Genérica: puta

Fonte: Elaborado pelas autoras.

A Figura 5 exibe um Operador de Escala Superlativa (OES): o adjetivo hiperbolizante puta, que intensifica um Núcleo Graduável (NG), preenchido por um substantivo $(\mathrm{N})$ ou por um adjetivo (ADJ).

Conforme evidenciam os números, puta gramaticaliza-se como ADJ ou ADV como expressão intensificadora. As 580 ocorrências de puta como intensificador já são suficientes para revelar um padrão de superlatividade. Sendo puta um adjetivo hiperbolizante, de acordo com alguns dicionários que consultamos, propomos, por ora, enquadrá-la na Construção Superlativa Genérica.

Apresentadas nossas buscas e realizadas nossa análise das expressões, tecemos algumas considerações sobre nosso processo investigativo. Chamou nossa atenção a quantidade de expressões para denotar uma mesma ideia, fato que não caracteriza novidade, e, sim, justifica os estudos sobre superlatividade, importantes para formalizar expressões superlativas/intensificadoras de uso costumeiro pelos falantes de Português Brasileiro.

Através de nossa pesquisa, obtivemos resultados consideravelmente profícuos, os quais nos permitiram evidenciar o uso significativamente efetivo das expressões investigadas. Além disso, a pesquisa nos corpora e no Google possibilitou o contato com formas diferentes daquelas quehavíamos pensado originalmente e nos permitiu detalhá-las e exemplificá-las.

Devido à quantidade de expressões que elegemos, o recorte analítico acabou por ser menos denso do que aqueles dos estudos revisados, o que se justifica pela natureza exploratória desta pesquisa, a partir da qual objetivamos reunir as construções superlativ as já estudadas e evidenciar as vastas possibilidades desse campo de estudo. Acreditamos que este estudo exploratório contém variados aspectos passíveis de aprofundamento teórico-analítico, tarefa para estudos futuros. 


\section{CONSIDERAÇÕES FINAIS}

Devido à natureza de nosso estudo, buscamos explorar expressões que denotam superlatividade/intensificação.

Realizadas as buscas nos corpora, as expressões foram contabilizadas e classificadas em termos de escopo, o que nos permitiu refletir sobre cada padrão evidenciado. Tri foi considerado como Construção Prefixal de Modificação de Grau, categoria formalizada por Carrara (2015); baita e puta, não tendo encontrado padrão específico nos estudos revisados, foram classificadas como Construções Superlativas Genéricas, conforme Machado (2011), que propõe uma construção genérica, a qual abrange o uso de advérbios de intensidade e sufixos. Baseando-nos nessa categorização e nos respectivos autores, criamos uma matriz construcional para cada expressão. Como foi observado, os núcleos graduáveis estendem-se a outras classes gramaticais, para além do adjetivo e do advérbio, diferentemente da Construção Superlativa Genérica Informal, proposta por Machado (2011), de acordo com a Figura 1. Observese a Figura 6, a seguir. Nela apresentamos o resultado de nossas análises através das matrizes construcionais propostas, evidencian do a relação entre as matrizes genéricas de superlatividade.

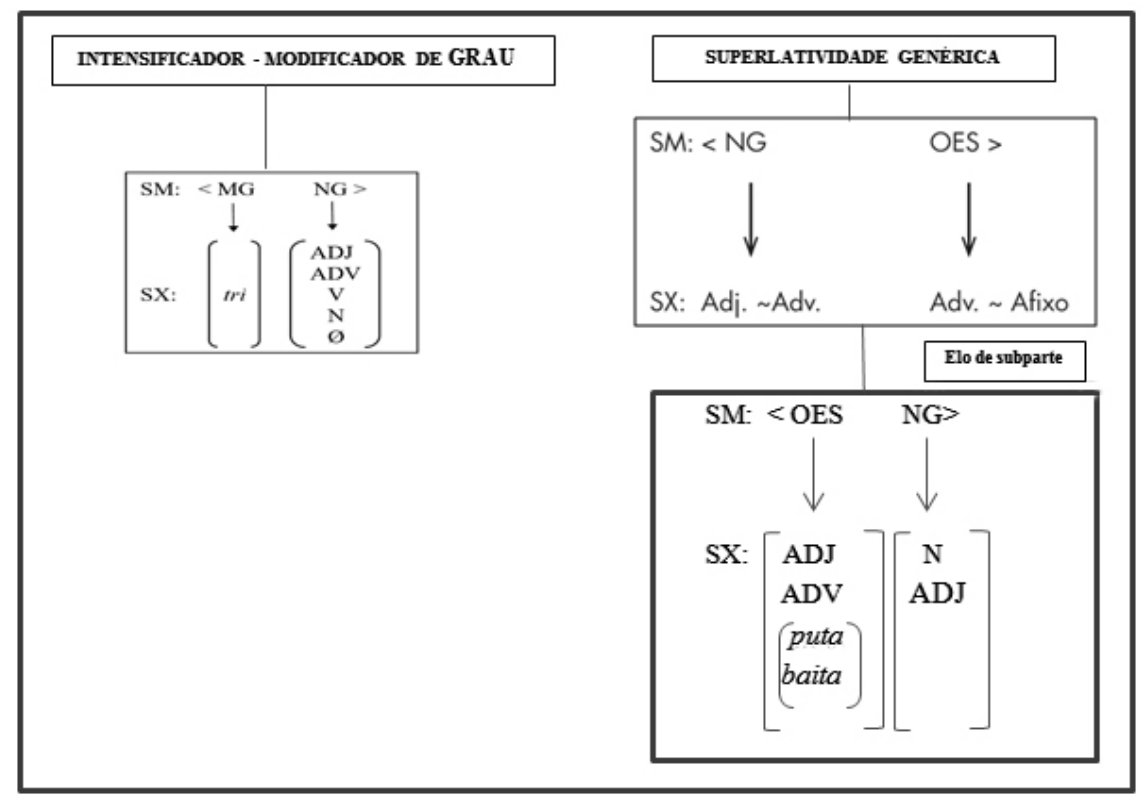

Figura 6: Síntese das matrizes construcionais

Fonte: Elaborado pelas autoras

De maneira geral, nossa pesquisa, assim como as demais que têm sido realizadas sobre a superlatividade sob a ótica da Gramática das Construções, reforça a ideia de que os recursos de expressão da superlatividade/intensificação são os mais variados, dada a criatividade e a produtividade intrínsecas à língua em uso, o que não consegue ser abarcado pelas restrições impostas pelas gramáticas normativas tradicionais.

\section{REFERENCIAS}

BOSSLE, B. Dicionário gaúcho brasileiro. Porto Alegre: Artes e Ofícios, 2003.

CARRARA, A. C. F. A construção prefixal de modificação de grau - uma abordagem construcionista da morfologia derivacional. 2015. 216 f. Tese (Doutorado em Linguística) - Faculdade de Letras, Universidade Federal de Juiz de Fora, Juiz de Fora, 2015.

CORPUS DO PORTUGUES.ORG. O corpus do Português. Disponível em <http://www.corpusdoportugues.org/>. Acesso em: out. 2016 a jun. 2017.

Forum lingüístic., Florianópolis, v.15, n.2, p.3072-3092, abr./jul. 2018 
CROFT, W.; CRUSE, D. A. Cognitive linguistics. Cambridge: Cambridge University Press, 2004.

EVANS, V. A glossary of cognitive linguistics. Salt Lake City: The University of Utah Press, 2007.

FERREIRA, A. B. de H. Novo dicionário Aurélio da língua portuguesa. 4. ed. Curitiba: Positivo, 2009.

FILLMORE, C. J. Innocence: a second idealization for linguistics. In: BERKELEY LINGUISTICS SOCIETY, 5, 1979, Berkeley. Proceedings... Berkeley, 1979. et al. Regularity and idiomaticity in grammatical constructions: the case of let alone. Language, v. 64, n. 3, p. 501-538, set. 1988.

FISCHER, L. A. Dicionário de porto-alegrês. 6. Ed. Porto Alegre: Artes e Ofícios, 1999.

GEIGER, P. (Org.). Novíssimo Aulete: dicionário contemporâneo da língua portuguesa. Rio de Janeiro: Lexikon, 2011.

GOLDBERG, A. Constructions at work. Oxford. Oxford University Press, 2006.

GOLDBERG, A. Constructions: a construction grammar approach to argument structure. Chicago: The University of Chicago Press, 1995.

HOUAISS, A. et al. Dicionário Houaiss da língua portuguesa. Rio de Janeiro: Objetiva, 2009.

KLEITON E KLEDIR. Deu pra ti. Disponível em: <https://www.letras.mus.br/kleiton-e-kledir/131060/>. Acesso em: mar. 2017.

LAKOFF, G. Women, fire, and dangerous things. Chicago: University of Chicago Press: 1987.

LARIÚ, N. Dicionário de baianês. [1992]. Disponível em: <http://www.folderpark.net/baian es/>. Acesso em: mar. 2017. Dicionário de baianês - parte 2: entrevista. Portal iBahia. 2014. Disponível em: < https://www.youtube.com/watch?v=KqTxbFb-GdU>. Acesso em: mar. 2017.

MACHADO, P. M. A construção superlativa sintética de estados absolutos com o sufixo -íssimo: um caso de Desencontro/ Mismatch morfológico. 2011. 139f. Dissertação (Mestrado em Linguística), Faculdade de Letras, Universidade Federal de Juiz de Fora, Juiz de Fora, 2011.

MIRANDA, N. S. Apresentação. In: MIRANDA, N. S.; SALOMÃO, M. M. M. (Org.). Construções do português do Brasil: da gramática ao discurso. Belo Horizonte: Editora UFMG, 2009a. p. 9-19.

MIRANDA, N. S. Construções gramaticais e metáfora. Gragoatá, Niterói, n. 26, p. 61-80, 1. sem. 2009 b.

MIRANDA, N. S.; MACHADO, P. M. Polaridades, intensidades e desencontros: uma construção superlativa de estados absolutos. Linha D'Água (Online), São Paulo, v. 27, n. 1, p. 117-137, jun. 2014. 
MIRANDA, N. S.; SALOMÃO, M. M. M. (Org.). Construções do português do Brasil: da gramática ao discurso. Belo Horizonte: Editora UFMG, 2009.

NUNES, Z. C. ; NUNES, R. C. Dicionário de regionalismos do Rio Grande do Sul. Porto Alegre: Martins Livreiro, 1984.

ROCHA, C. A. de M.; ROCHA, C. E. P. de M. Dicionário de locuções e expressões da língua portuguesa. Rio de Janeiro: Lexikon, 2011.

SALOMÃO, M. M. M. Gramática das construções: a questão da integração entre sintaxe e léxico. Veredas. Revista de Estudos Linguísticos, Juiz de Fora, v. 6, n. 1, p. 63-74, jan./jun. 2002.

SALOMÃO, M. M. M. Teorias da linguagem: a perspectiva sociocognitiva. In: MIRANDA, N. S.; SALOMÃO, M. M. M. (Org.). Construções do português do Brasil: da gramática ao discurso. Belo Horizonte: Editora UFMG, 2009a. p. 20-32.

SALOMÃO, M. M. M. Tudo certo como dois e dois são cinco: todas as construções de uma língua. In: MIRANDA, N. S.; SALOMÃO, M. M. M. (Org.). Construções do português do Brasil: da gramática ao discurso. Belo Horizonte: Editora UFMG, $2009 \mathrm{~b}$. p. 33-74. 